\title{
26430 - PULMONARY HYPERTENSION AND AORTIC VALVE REPLACEMENT
}

\section{Juan C. Bianco MD, André Y Denault, MD, FRCPC; Pierre Couture, MD, FRCPC; Baqir Qizilbash, Michel Carrier, MD; Montreal Heart Institute, Montreal, QUEBEC, Canada}

INTRODUCTION: Relative pulmonary hypertension (PHT) defined as mean arterial pressure (MAP) / mean pulmonary artery pressure (MPAP) ratio has been associated with increased hemodynamic complications after cardiac surgery (1). However the impact of the MAP/MPAP ratio in aortic valve replacement (AVR) on long-term survival is unknown.

METHODS: After obtaining approval from the Research and Ethics Committee of the Montreal Heart Institute on the use of the perioperative and valve clinic database, we studied consecutive adult patients having undergone an AVR between January and December 1999 that were followed-up for 5 years. We analyzed the demographic data and the hemodynamic profile obtained after the induction of anesthesia. This included MAP, MPAP and the relative PHT (MAP/MPAP) (normal value $=4$ and lower values associated with more severe PHT) (1). Exclusion criteria were AVR combined with mitral valve surgery, Bentall, homograft and Ross's procedures. The primary endpoint was 5-year survival. T-test and Chi-square were used to compare continuous and categorical variables and logistic regression analysis performed to identify predictors of mortality. The $\mathrm{p}<0.05$ is significant.

RESULTS: 184 patients were included (12\% of the population operated in 1999). The mean age was $64 \pm 13$ years with $61 \%$ male. The 5-year actuarial survival was $84.7 \%$. Among the $30(16.3 \%)$ patient deaths, there were 22 males and 8 females $(\mathrm{p}=0.14)$. Those who died were older $(73 \pm 5$ vs $62 \pm 13, \mathrm{p}<0.0001)$, had worse relative PHT (MAP/MPAP ratio $3.36 \pm 1.32$ vs $3.96 \pm 1.43, \mathrm{p}=0.034$ ). In the univariate analysis the MAP/MPAP ratio was significant $(\mathrm{p}=0.0371)$ however only age remains significant in the multivariable model (odds ratio:1.14; 95\% confidence interval: 1.07-1.22; $\mathrm{p}<0.0001$ ).

CONCLUSION: Pulmonary hypertension is associated with an increased 5-year mortality, but on multivariate analysis age was the strongest predictor.

REFERENCE: 1) J Thorac Cardiovasc Surg 2006 (in press). 